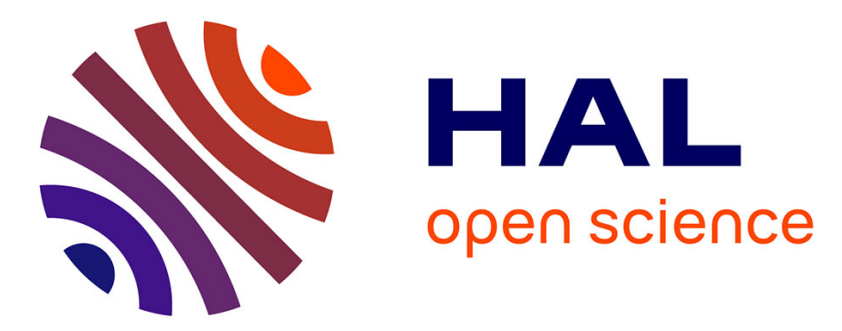

\title{
Veneer grades, recoveries, and values from 5-year-old eucalypt clones
}

\author{
Jianzhong Luo, Roger Arnold, Shiqi Ren, Ying Jiang, Wanhong Lu, Yan \\ Peng, Yaojian Xie
}

\section{- To cite this version:}

Jianzhong Luo, Roger Arnold, Shiqi Ren, Ying Jiang, Wanhong Lu, et al.. Veneer grades, recoveries, and values from 5-year-old eucalypt clones. Annals of Forest Science, 2013, 70 (4), pp.417-428. $10.1007 / \mathrm{s} 13595-013-0268-\mathrm{x}$. hal-01201482

\section{HAL Id: hal-01201482 \\ https://hal.science/hal-01201482}

Submitted on 17 Sep 2015

HAL is a multi-disciplinary open access archive for the deposit and dissemination of scientific research documents, whether they are published or not. The documents may come from teaching and research institutions in France or abroad, or from public or private research centers.
L'archive ouverte pluridisciplinaire HAL, est destinée au dépôt et à la diffusion de documents scientifiques de niveau recherche, publiés ou non, émanant des établissements d'enseignement et de recherche français ou étrangers, des laboratoires publics ou privés. 


\title{
Veneer grades, recoveries, and values from 5-year-old eucalypt clones
}

\author{
Jianzhong Luo • Roger Arnold • Shiqi Ren • Ying Jiang • \\ Wanhong Lu • Yan Peng • Yaojian Xie
}

Received: 29 May 2012 / Accepted: 23 January 2013 /Published online: 22 February 2013

(C) INRA and Springer-Verlag France 2013

\begin{abstract}
- Context Processing young, small eucalypt logs into veneer is a burgeoning industry across southern China. However, plantations supplying these logs were mostly established for pulpwood; little information is available on variation and selection among commercial eucalypt clones/varieties in regards to suitability for veneer production.

- Methods Tree growth and log form were assessed on 11 eucalypt clones from a 5-year-old trial in southern China. Logs from these were rotary peeled for veneer; recovery percentages plus a range of quality and value traits were assessed on the outturn.

- Results Tree volumes, green veneer recovery ratios (\%), veneer quality grades, $\log$ value, and value $\mathrm{m}^{-3}$ varied significantly among both clones and log positions up the stem. The
\end{abstract}

Handling Editor: Jean-Michel Leban

Contributions of the co-authors Jianzhong Luo: designing the sampling strategy and assessment traits, background research, field logistics, coordinating the research project, writing the paper

Roger ARNOLD: advising on design of study and data collection, organizing data, carrying out data analyses, writing the paper

Shiqi REN: designing the sampling strategy and assessment traits, background research, field logistics, assessments and data collection, writing the paper

Ying JIANG: field logistics, assessments and data collection, compiling data, and pre-processing data

Wanhong LU: field logistics, assessments and data collection, compiling data

Yan PENG: designing the sampling strategy and assessment traits, background research, writing the paper

Yaojian XIE: background research, coordination the research project, managing project funding, writing the paper

J. Luo $\cdot$ R. Arnold $(\bowtie) \cdot$ W. Lu $\cdot$ Y. Peng $\cdot$ Y. Xie

China Eucalypt Research Centre, 30 Mid Renmin Dadao,

Zhanjiang, Guangdong 524022, China

e-mail: roger.arnold@y7mail.com

S. Ren $\cdot$ Y. Jiang

Guangxi Forest Research Institute, Nanning, Guangxi, China clone with the best veneer recovery ratio $(50.5 \%)$ provided nearly twice that of the poorest clone $(28.4 \%)$. Average veneer value $\log ^{-1}$ by clone ranged from RMB 6.7 (US\$1) up to RMB 15.1 (US\$2) and average value $\mathrm{m}^{-3}$ by clone ranged from $589 \mathrm{RMBm}^{-3}$ (US\$88) up to $925 \mathrm{RMBm}^{-3}$ (US\$139). Overall, sweep was the key factor influencing veneer recovery ratio and value. Knots, especially dead knots, holes and splitting were major factors influencing veneer quality grade. Middle and upper logs had significantly higher veneer recoveries, grades, and values $\mathrm{m}^{-3}$ than the lower logs. - Conclusions Excellent potential exists for selecting among eucalypt clones, and even among log positions within trees, for optimizing veneer production.

Keywords Eucalypt clone · Peeled veneer · Veneer grade . Veneer recovery ratio $\cdot$ Wood properties

\section{Introduction}

Production of plywood in China has increased rapidly over the last 20 years from 2.1 million $\mathrm{m}^{3}$ in 1993 to more than 50 million $\mathrm{m}^{3}$ in 2010 (Wood Markets 2011; Petry et al. 2010). In 2003, China overtook USA to become the world's largest plywood producer and by 2009 China accounted for around $30 \%$ of global plywood exports (Wan 2009).

China's rapid increase in plywood production has created buoyant demand for domestically produced veneer logs as well as necessitating greater log imports. In recent years, many Chinese plywood manufacturers have begun to use small logs (small end diameters down to $6 \mathrm{~cm}$ or less) from the country's fast-growing high-yielding plantations to provide core veneers for higher-grade plywood as well as both core and surface veneers for industrial and construction grades of plywood.

Eucalypts are among the most important fast-growing high-yielding plantation species in China with the area 
planted to these species now totaling more than 3.1 million ha (Fang 2008 and ITTO 2011). While most of the country's existing eucalypt plantation resource was established for a pulpwood end-product objective (Chen et al. 2010), it is now anticipated that up to half of the $\log$ production from these plantations will be diverted to veneer (Anonymous 2011). This is the result of a combination of strong demand for domestically produced veneer logs to replace expensive imported logs; continued rapid growth in veneer and ply production in China; and, increasing acceptance of the suitability of young ( 5 years old or less), small diameter eucalypt logs as sources of both core and surface veneers in plywood manufacture in China.

To date the selection of clones/varieties by growers for eucalypt plantation establishment and tree improvement efforts in China have focused primarily on key traits for pulp production - namely volume, wood basic density, and kraft pulp yield (Turnbull 2007; Luo et al. 2012). Little work has yet been done to select superior eucalypt clones/varieties in China in regards to their suitability for veneer production.

Logs from most Chinese eucalypt plantations have attributes, such as low taper, good straightness, desirable wood density, stiffness, and wood surface texture (Jiang et al. 2007), that make them desirable for solid wood applications including veneer production. However, there is little information available on the variability of such traits between commercial varieties/clones when grown under standard plantation conditions used in southern China and how such variation can affect both grades and recoveries of veneer.

Anecdotal evidence from veneer mills in western Guangdong and southern Fujian provinces indicate marked differences exist among some key commercial eucalypt clones for both recovery percentages and veneer quality. Such differences have been confirmed by a preliminary study we conducted, which revealed variations in average green veneer recovery by clone from 25 to $48 \%$ and in recovered veneer values $\left(\mathrm{RMB} \mathrm{m}^{-3}\right)$ by clone from 450 to 681 (Ren et al. 2010a, b). However, the validity of that study's findings was complicated by differences among clones potentially being confounded with both site differences (clones were sampled from disparate block plantings) and spacing (stand stocking) differences between clones. Also, sample trees were over 6 years of age; a year older than harvest age for most eucalypts in southern China.

A separate recent study on veneer recovery and values from eucalypts in China, Peng et al. (2011), also found significant differences among clones for both recoveries (range of clone averages, 57 to $68 \%$ ) and veneer values (range of clone averages, 646 to $905 \mathrm{~m}^{-3}$ ). However, for their study all five clones examined were of just one hybrid combination, Eucalyptus urophylla $\times$ grandis, and at 12 years of age when sampled, the trees were more than double the current average harvest age in China.

Even so, such evidence of important variation among eucalypt varieties is supported by results from Australian studies on peeled eucalypt veneer; Thomas et al. (2009) found that veneer recoveries among five eucalypt taxa varied from 30 to $55 \%$ and percentages of different veneer grades recovered also varied among taxa. A later study on peeled veneer with Eucalyptus nitens by Blakemore et al. (2010) found the lowest logs provided higher recoveries (non-reject grade veneer recovery of $58 \%$ for unpruned trees) and superior grades of veneers than logs from higher up the trees (non-reject grade veneer recoveries from middle and upper logs of 54 and $27 \%$ respectively for unpruned trees).

The objective of this current study was to examine the magnitude of variation among a range of commercial eucalypt clones in veneer grade and value traits, and to examine what traits measurable on logs are associated with variation in veneer quality and veneer log values. To do this, trees of 11 eucalypt clones were sampled from a field trial in China's Guangdong province at age 5 years. The standing trees were assessed for growth traits and after felling, the exterior form and quality of cut logs were assessed. Veneer obtained from the logs was measured (to estimate recovery), graded according to Chinese grading standards (so that value measures could be estimated) and a range of quality traits assessed. Regression analyses were then used to examine relationships of the various traits with veneer recovery, quality, and value.

\section{Materials and methods}

\subsection{Trial site}

The field trial was located in Suixi County of Zhanjiang City in southwest of Guangdong Province, China-latitude $21^{\circ} 30^{\prime} \mathrm{N}$, longitude $111^{\circ} 38^{\prime} \mathrm{E}$, elevation about 100 ma.s.l. This site has a humid, tropical, maritime monsoon climate with mean annual temperature of $23.1{ }^{\circ} \mathrm{C}$, absolute minimum temperature of $3.6{ }^{\circ} \mathrm{C}$, absolute maximum temperature of $38.8{ }^{\circ} \mathrm{C}$, mean annual rainfall of $1,567 \mathrm{~mm}$, and mean annual evaporation of $1,763 \mathrm{~mm}$. Most rainfall occurs during spring and summer; autumn and winter being drier. The site's soil is a red lateritic clay loam derived from volcanic parent material with $\mathrm{pH}$ in the range $4.5-5.5$; its topography is predominantly flat.

\subsection{Genetic material}

This study included 11 eucalypt clones-details provided in Table 1-and these included some of the most 'popular' commercial clones (i.e., clones most planted as judged by surveys of commercial nurseries) currently used for eucalypt plantation establishment in southern China. Their popularity is due to a combination of high growth rates, good stem form, ease of propagation, reasonable wood properties (primarily wood basic density), and relatively wide adaptability. 
Table 1 Taxonomy of the eucalypt clones in the field trial in Suixi County, China

\begin{tabular}{lll}
\hline $\begin{array}{l}\text { Clone } \\
\text { number }\end{array}$ & Species & $\begin{array}{l}\text { Local identity } \\
\text { code }\end{array}$ \\
\hline 1 & E. grandis $\times$ tereticornis \\
2 & E. urophylla $\times$ tereticornis & DH201-2 \\
3 & E. urophylla $\times$ grandis & SH7 \\
4 & E. saligna & DH32-22 \\
5 & E. urophylla $\times$ grandis & SG1 \\
6 & E. urophylla & EC33 \\
7 & E. urophylla $\times$ grandis $\times$ E. urophylla $\times$ EC42 \\
8 & tereticornis & EC40 \\
9 & E. grandis & EC48 \\
10 & E. tereticornis & LM1 \\
11 & E. urophylla $\times$ tereticornis & TM3 \\
\hline
\end{tabular}

\subsection{Trial design and establishment}

The trial was planted in May 2004 with three replicates in a randomized complete block design. Each of the 11 clones was represented as a block plot of two rows each of five trees (ten tree plots) in each replicate, with $2.0 \mathrm{~m}$ between trees within rows and $3.0 \mathrm{~m}$ between rows - an initial stocking of 1,667 tree $\mathrm{ha}^{-1}$. This initial stocking is that most commonly used for eucalypt plantations in southern China (Chen et al. 2010).

\subsection{Assessments on trees and logs}

In September 2009 at approximately age 5 years, all living trees were assessed for diameter at breast height $(1.3 \mathrm{~m})$ over bark, and total height. Age 5 years is about the average rotation length for most eucalypt plantations in China (see, Chen et al. 2010 and Turnbull 2007). The first three acceptable trees (trees stunted or malformed were regarded as unacceptable) with around average $\mathrm{DBH}$ (clone mean $\pm 30 \%$ ) in the first replicate were then selected for sampling and these trees were felled to a stump height of approximately $20 \mathrm{~cm}$ - a total of 33 tree sample trees being felled (11 clones $\times 3$ trees). Only five stunted or malformed trees were encountered in the course of sampling (from four different clones); their condition was primarily attributable to mechanical damage suffered during mechanical weed control operations earlier in the life of the trial (between ages 6 to 24 months), evident from wound scars on their lower trunks.

Total height was measured on felled trees to verify the accuracy of total heights measured on the standing trees. The felled trees then were cross-cut into $1.3 \mathrm{~m}$ log lengthsthe standard length sought by many veneer manufactures in southern China. From each felled tree the first, third, and fifth $\log$ (progressing upwards from the butt) were collectedproviding a total of $99 \operatorname{logs}$ from the 33 trees felled ( 3 logs tree ${ }^{-1} \times 3$ trees clone $e^{-1} \times 11$ clones). These logs were then stored under shade to prevent excessive water loss. Log identities, including source clone, tree, and position within the tree (i.e., first, third, or fifth $\log$ ), were carefully maintained through to completion of veneering. Logs were processed into veneer within 7 days of felling - relative humidity during this period remained above $65 \%$ for almost the entire period. On each of these logs, the following traits were measured the day before logs were processed into veneer:

- Exact length

- Maximum and minimum diameter (under bark) of the large end

- Maximum and minimum diameter (under bark) of the small end

- Sweep - maximum deviation of the center line of the log from a straight line between the midpoints of the two ends

- End splits at the large and small ends-measured according to the technique described by Yang (2005), this involved recording the maximum split length on the $\log$ end and on the log surface (see Fig. 1)

- Number of knots and branch stubs visible on log surface (before removing bark)

From this data, the following parameters were derived:

- $\quad$ Log volume $(V)=\left[R_{\mathrm{B}}^{2}+R_{\mathrm{T}}^{2}+\left(R_{\mathrm{B}} \times R_{\mathrm{T}}\right)\right] \times \frac{1}{3} \times \pi \times L$ Where: $V$ is the log volume $\left(\mathrm{m}^{3}\right)$

$R_{\mathrm{B}}=$ average radius at bottom of $\log (\mathrm{m})$

$$
\begin{aligned}
& =\left[\left(D_{1}{ }^{2}+D_{2}^{2}\right) / 4\right]^{0.5} \\
R_{\mathrm{T}} & =\text { average radius at top of } \log (\mathrm{m}) \\
& =\left[\left(D_{3}{ }^{2}+D_{4}{ }^{2}\right) / 4\right]^{0.5}
\end{aligned}
$$

$D_{1}$ and $D_{2}$ are the maximum and minimum diameters of the large end of the $\log (\mathrm{m})$

$D_{3}$ and $D_{4}$ are the maximum and minimum diameters of the small end of the $\log (\mathrm{m})$

$L$ is the log length (m)

$\pi$ is the constant $\mathrm{Pi}=3.141593$ (six decimal places)

- $\quad$ Sweep $(Z)=S / L \times 100$;

Where: $Z$ is $\%$ sweep

$S$ is the maximum deviation of the center line of the $\log$ from a straight line between the mid points of the two ends (m)

$L$ is as defined above

- $\operatorname{Taper}(T)=\left[\left\{\left(D_{1}+D_{2}\right) \times \frac{1}{2}\right\}-\left\{\left(D_{3}+D_{4}\right) \times \frac{1}{2}\right\}\right] / L \times 100$

Where: $T$ is $\% \log$ taper

$D_{1}, D_{2}, D_{3}, D_{4}$, and $L$ are as defined above.

- Circularity $(C)=\left(C_{L}+C_{S}\right) / 2$;

Where: $C$ is \% circularity 
$C_{L}=\left(D_{2} / D_{1}\right) \times 100$

$D_{1}$ and $D_{2}$ are as defined above

$C_{S}=\left(D_{4} / D_{3}\right) \times 100 ;$

$D_{3}$ and $D_{4}$ are as defined above.

- Log end check index (calculated according to Yang's 2005 Split Index 2)-see Fig. 1:

End check index $(\mathrm{CI})=\left[\left(\mathrm{SL}_{\mathrm{END}}{ }^{2} / 2\right)+\left(\mathrm{SL}_{\mathrm{END}} \times \mathrm{SL}_{\mathrm{SURFACE}}\right)\right]$ $/ R^{2}$ MEAN (mm)

Where: $\mathrm{SL}_{\mathrm{END}}$ is the maximum split length on the log end

$\mathrm{SL}_{\mathrm{SURFACE}}$ is the maximum split length on the log's side surface (mm)

$R_{\text {MEAN }}$ is the mean radius of the log end (mm)

\subsection{Veneer peeling and assessment}

All sample logs were debarked by hand and then processed using a Chinese manufactured rotary veneer peeling lathe, powered by a 20.3-KW electrical engine, set to peel veneer of $1.7 \mathrm{~mm}$ green thickness down to a $2 \mathrm{~cm}$ core diameter. Peeling down to cores diameters of around $2 \mathrm{~cm}$ is fairly standard practice among the countless small eucalypt mills

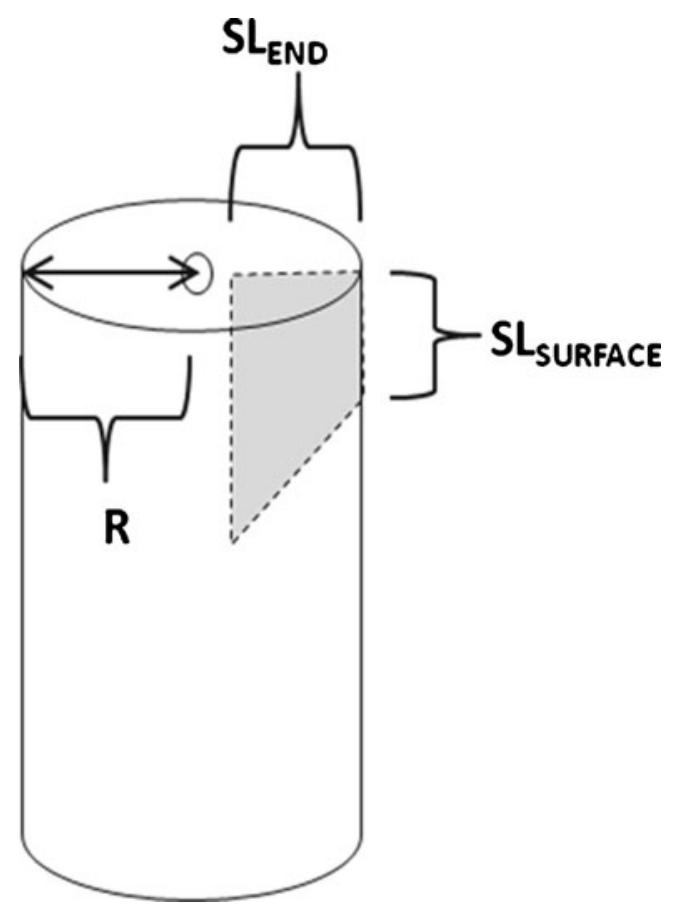

Fig. 1 Illustration of the parameters $\mathrm{SL}_{\mathrm{END}}$ (maximum split length on $\log$ end), SL SURFACE (maximum split length on log's side surface), and $R$ (radius of the end log end where split occurs) used in calculating log end check index processing young, small diameter eucalypt logs in southern China.

The veneer sheets produced were cross-cut at $640 \mathrm{~mm}$ intervals giving sheets of approximately $1,300 \times 640 \mathrm{~mm}$ (longitudinal $\times$ tangential). Only whole sheets were collected for examination; green volume recoveries for each log were calculated from dimensions of individual whole sheets. Partial or incomplete sheets were not included in green recovery, but were relegated to residues. Residues from rotary veneer manufacture have a value of RMB $400 \mathrm{~m}^{-3}$ (approximately US\$63 $\mathrm{m}^{-3}$ ) as a source of wood fiber in southwestern Guangdong; there is strong demand for eucalypt pulpwood, including veneer manufacturing residues, from both fiber board factories and pulp mills.

As a preceding investigative study suggested that both dead knot number and size were key factors influencing grade (Ren et al. 2010a), dead knot numbers by size classes were examined on each sheet to assign a dead knot index as follows:

1 - No limitation on number of dead knots with diameters $\leq 2 \mathrm{~mm}$, dead knots 2 to $4 \mathrm{~mm} \leq 2 \mathrm{~m}^{-2}$

2 - No limitation on number of dead knots with diameters $\leq 4 \mathrm{~mm}$, knots $>4 \mathrm{~mm}$ diameter $\leq 3 \mathrm{~m}^{-2}$

3 - No limitation on number dead knots with diameters $\leq 15 \mathrm{~mm}$, knots $>15 \mathrm{~mm}$ diameter $\leq 4 \mathrm{~m}^{-2}$

4 - No limitation on number of dead knots, but maximum size $\leq 30 \mathrm{~mm}$ diameter

5 - No limitation on number and size of dead knots

For splits in each sheet: number, maximum length, and maximum width were assessed to obtain a veneer end split index value as follows:

1 - $\leq 2$ enclosed splits, total length $\leq 200 \mathrm{~mm}$

2 - Width $\leq 1.5 \mathrm{~mm}$, length $\leq 400 \mathrm{~mm}, \leq 4$ per sheet

3 - Width $\leq 3 \mathrm{~mm}$, length $\leq 600 \mathrm{~mm}, \leq 4$ per sheet

4 - Width $\leq 5 \mathrm{~mm}$

5 - Width $>5 \mathrm{~mm}$

Counts of live knots per unit area $\left(\mathrm{m}^{-2}\right)$ and holes per unit area $\left(\mathrm{m}^{-2}\right)$ were also recorded for each veneer sheet obtained. These measures were used to directly provide indices of live knots (i.e., live knot index) and of holes (i.e., hole index), respectively.

All sheets were then visually graded according to the Chinese standard "LY/T 1599-2002" (CNAS 2002); this provides criteria for five veneer grades (see Appendix 1). Veneer sheets were valued in accordance with local market prices (at mill gate) current at the time the study was conducted, which were as follows:

Grade 1 RMB 2,400 $\mathrm{m}^{-3}$ (approximately US\$376 $\mathrm{m}^{-3}$ ) Grades 2 and 3 RMB 2,000 $\mathrm{m}^{-3}$ (approximately US $\$ 314 \mathrm{~m}^{-3}$ ) 
Grades 4 and 5 RMB $1,800 \mathrm{~m}^{-3}$ (approximately US $\$ 282 \mathrm{~m}^{-3}$ )

Veneer values $\log ^{-1}$ and tree ${ }^{-1}$ were obtained as the sum of the value of individual veneer sheets obtained from each $\log$ and tree, respectively; tree veneer values represented the sum of the values from $\operatorname{logs} 1,3$, and 5 . Total value was obtained as the sum of the value of individual veneer sheets plus the value of residue.

\subsection{Statistical analyses}

To conduct two-way analyses of variance to examine the effects of clone, log-height, and the clone $\times$ log-height interaction, data on veneer sheet properties were reduced to plot mean values. The univariate procedure of SAS statistical analyses package (SAS Institute Inc 1999) was used to check if the distributions of this plot mean trait data were approximately normal; all data had reasonable conformity to key analyses of variance assumptions.

The general linear models procedure (PROC GLM in SAS) was used to compute two-way analyses of variance and trait means for each clone and log position. The correlation procedure (PROC COR) was used to obtain correlations and the significance of these, between pairs of traits for veneer recovery, veneer grade, and log and tree values with various tree, $\log$, and veneer quality traits. The regression procedure (PROC REG) was used to carry out stepwise regression analyses to examine what combinations of traits could be useful in predicting veneer grades, recoveries, and values. In the latter analyses, sequences of multiple regression equations were computed in a stepwise manner for each relationship, using forward selection of independent trait variables with an entry statistic of $P \leq 0.10$.

\section{Results}

\subsection{Tree and log traits}

Two-way analyses of variance revealed large, significant differences among clones and log positions for all traits assessed on logs and veneer sheets (Table 2). In contrast, clone $\times \log$ interaction effects for most traits were not significant, implying that patterns of variations in traits between logs did not differ between clones.

The clones with the largest tree volumes (under-bark), clones 1 and 5, also had the largest average log small end diameters and the lowest average taper (Table 3). However, the same clones also had higher log end-check indices (unfavorable) and one, clone 1, had the second worst (i.e., highest) sweep. Of the clones with the lowest volumes, clones 7, 10, and 11, the former (clone 7) had one of the highest (i.e., best) circularities; the latter (clone 11) had the worst sweep and highest number of visible knots on its logs; and clone 10 had the second highest taper. However, of these lower volume clones, clones 10 and 11 had the lowest end-check indices.

In terms of differences between log positions, the lower logs had the worst sweep (i.e., highest), circularity (lowest), and taper (highest) yet the best log end check indices (lowest) and the lowest number of visible knots out of the three log positions (Table 3). Middle logs on average had the best sweep (lowest), intermediate circularity, and taper, and the worst (highest) end-check indices and number of visible knots. The higher logs had intermediate sweep, log check indices, and number of visible knots while having the best circularity (highest) and taper (lowest).

Sweep and dead knot index were the only traits with significant clone $\times \log$ interaction effects (Table 2). Perusal of summary data revealed that some clones, such as 2,3 , and 5 , had higher sweep in their lower logs relative to the middle and upper logs while many other clones, especially 1,13 , and 16 , showed relatively consistent taper from the lower to the upper logs. However, there was no obvious association between such patterns and the taxa of clones. For dead knot index, the lower logs of clones 2, 3, and 10 showed markedly lower dead knot indices relative to their middle and upper logs while in most other clones dead knot indices were more consistent in the lower, middle, and upper logs.

\subsection{Veneer recovery, veneer properties, and values}

By clone, green veneer recovery varied significantly from a low of $28.4 \%$ for clone 11 up to $50.5 \%$ for clone 8 (Table 3), and all but three clones achieved green recoveries over $40 \%$. The clones that provided the highest volumes of veneer were clones 8 and 9 while those with the lowest volumes were clones 10 and 11 . The same clones provided the highest and lowest values of veneer per log and per $\mathrm{m}^{3}$, respectively, which might have been anticipated given both the relatively small variation among clones for average veneer grade and low premiums associated for increments in veneer grades from 4 to 3 . Even so, veneer values per log for the best two clones, 8 and 9, were nearly double those of the poorest clones, 10 and 11. Addition of the residue value to the veneer value to provide a total value per log did not significantly change the value rankings for clones, nor the differentials between the best and poorest clones.

Ranking of clones by total value per unit volume (RMB $\mathrm{m}^{-3}$ ) differed markedly to the ranking based on veneer value $\log ^{-1}$ (RMB $\log ^{-1}$; Table 3). Clones 8 and 9 had the highest and third highest value $\mathrm{m}^{-3}$, respectively and the highest veneer recoveries. While the former clone also had the best average veneer grade, clone 9 was one of the poorest by 


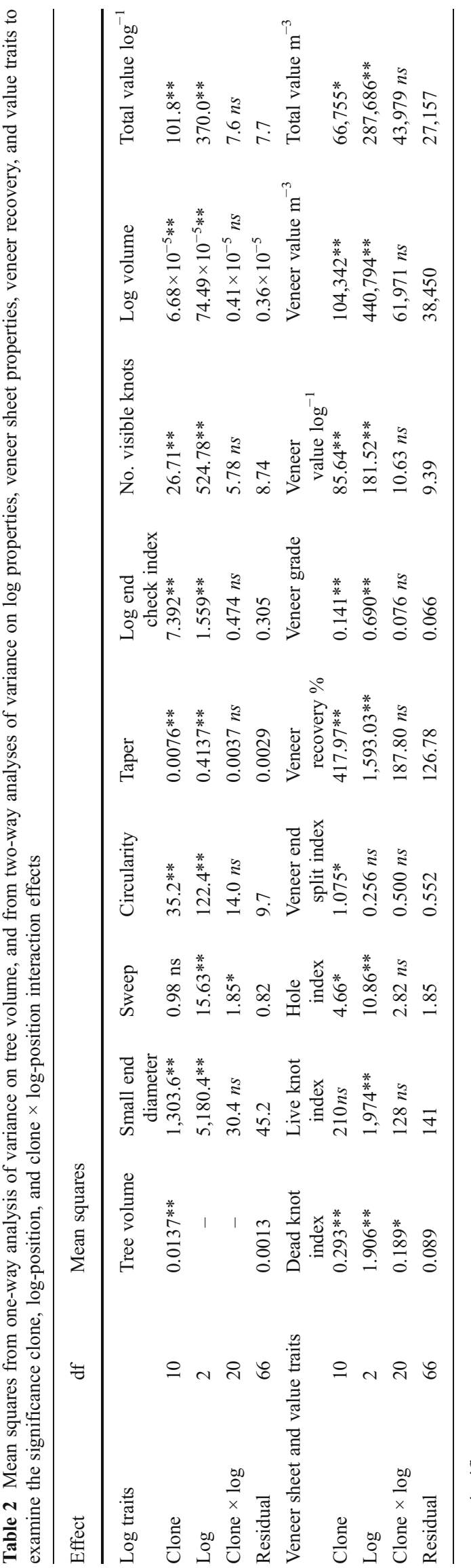

veneer grade. The clones with the lowest values $\mathrm{m}^{-3}$, clones 10 and 11 , had the lowest recoveries and were both among those with the poorest average veneer grades.

Just as there were significant differences among clones for log end check index (Tables 2 and 3), significant differences were also observed among clones for veneer sheet end split index as well as all other traits evaluated on their veneer. While the actual magnitude of the variation in some veneer traits seemed relatively small, such as average veneer grade (range 3.51 to 4.00), the variations among clones for other traits such as number of live knot index (range 11.7 to 27.5) and veneer sheet end split index (range 2.46 to 3.69) were more substantial.

Logs from different heights showed marked, significant differences in most veneer traits, veneer recoveries, and values (Tables 2 and 3). The lower logs yielded significantly lower veneer recoveries $(36.7 \%)$ compared to middle and upper logs (recoveries of 50.5 and $44.4 \%$, respectively), due to lower logs having higher sweep and taper. Even so, middle logs had a significantly higher average end check index (indicating more end checks) than either lower or upper logs, as well as diameters significantly less than the lower logs.

None of the veneer sheets obtained in this study qualified as grade 1 veneer and less than $2 \%$ of all sheets qualified as grade 2 (Fig. 2). The vast majority of sheets ( $>95 \%$ ) were of mediocre quality being categorized as either grade 3 or grade 4 . Less than $3 \%$ were relegated to the lowest quality category, grade 5 . Perusal of the raw data indicated that it was generally dead knots which tended to be the key determinant of veneer grade. Given that most of the sheets obtained were either of grades 3 or 4 and that value differentials between these grades were relatively small (RMB $200 \mathrm{~m}^{-3}$ of sheets, or approximately $10 \%$ ), the grade differences obtained had relatively small impact on log and tree values for the clones and logs in this study.

Log position (height) also proved to have a significant effect on proportional recovery of different veneer grades (Fig. 2). Across all clones the lower logs had the lowest (i.e., best) average grade compared to middle and upper logs (Table 3) as they provided a higher proportion of grade 3 veneer and a lower proportion of grade 4 veneer (Fig. 2). Grade proportions from the middle and upper logs were very similar and showed no significant differences (Table 3 ).

\subsection{Correlations}

Tree, log, and veneer sheet traits that showed one or more significant correlations with veneer grade, recovery, and/or value traits on a tree mean basis are presented in Table 4 . With average veneer grade, only veneer end split index $(r=$ $0.40)$, dead knot index $(r=0.63)$, and live knot index $(r=$ $0.50)$ showed significant correlations. This implies that 


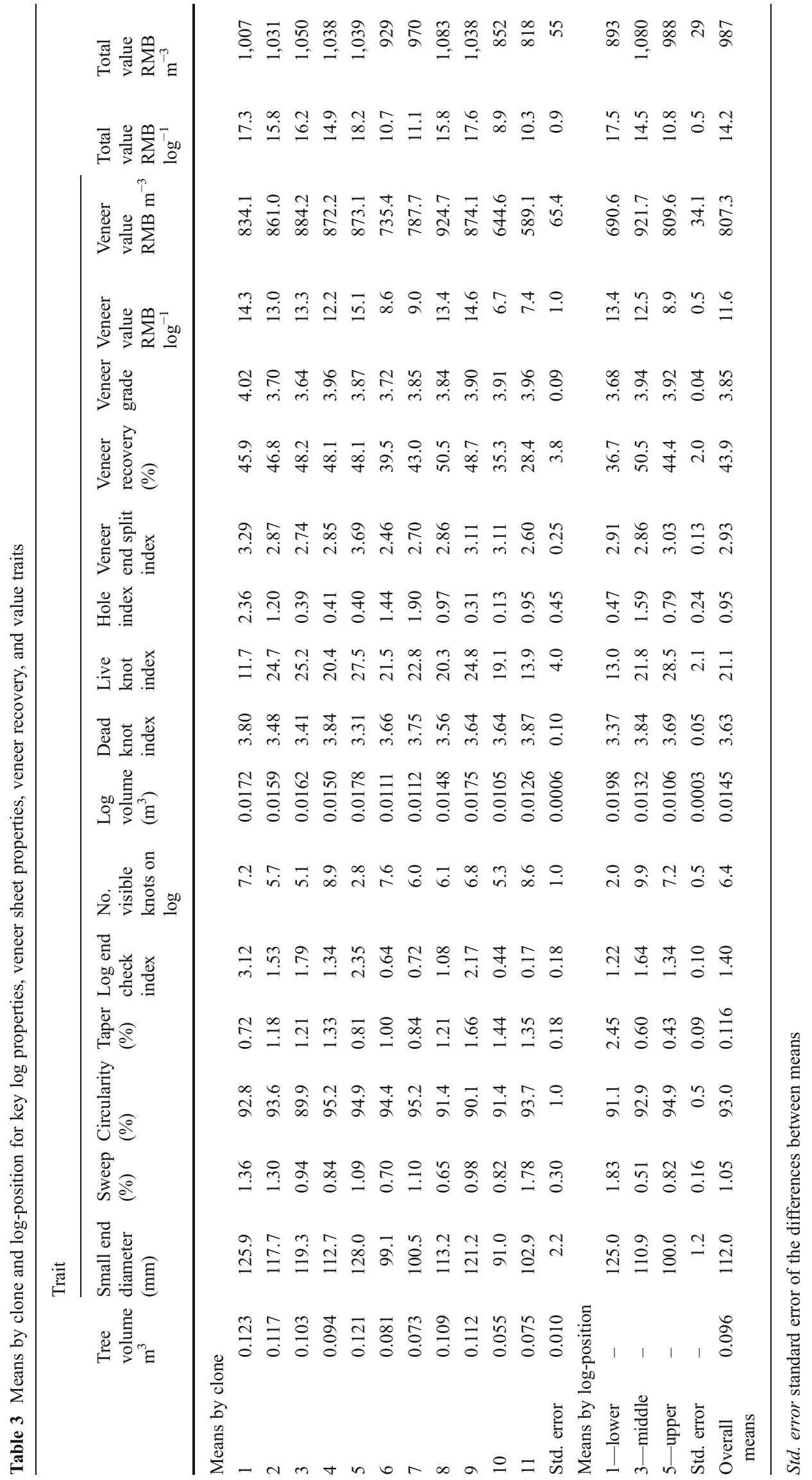




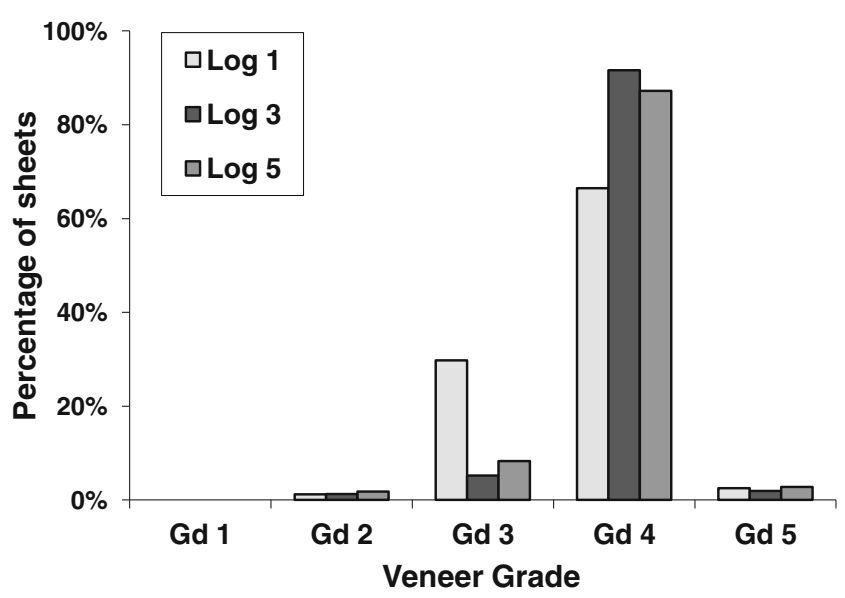

Fig. 2 Proportions of different veneer grades obtained from lower (log $1)$, middle $(\log 2)$, and upper $(\log 5) \operatorname{logs}$

lower end split indices, lower dead knot indices, and/or fewer live knots were associated with better veneer grades (i.e., numerically lower veneer grades).

The live knot index along with a number of other traits, also showed significant correlations with recovery percentage (Table 4); the others being DBH $(r=0.36)$, tree volume $(r=0.52)$, average small end diameter $(r=0.49)$, taper $(r=$ $-0.38)$, and $\log$ end check index $(r=-0.53)$. This implies that larger diameter logs, lower taper, less end-checking, and/or fewer live knots $\mathrm{m}^{-2}$ provided higher veneer recoveries.

For veneer value tree ${ }^{-1}$, total value tree $e^{-1}$, and total value $\mathrm{m}^{-3}$, the traits which showed significant correlations were $\mathrm{DBH}$, tree volume, small end diameter, and log end check index (Table 4). Of these, the strongest correlations were of small end diameter with total value tree ${ }^{-1}(r=0.94)$ and tree volume with total value $\mathrm{m}^{-3}(r=0.56)$. With the latter trait, average taper and live knot index also showed significant correlations ( $r=-0.36$ and -0.57 , respectively).
To examine combinations of traits which might be able to efficiently predict veneer grades, percentage recovery of veneer, and $\log$ values, stepwise regression analyses were carried out on both whole tree data (i.e., including values from $\operatorname{logs} 1,3$, and 5 ) and then separately for logs from different heights - results are shown in Table 5. Traits associated with the largest percentage of the variance in average veneer grade (on a whole tree basis) were both dead knot index (partial $R^{2}=0.54$ ) and end splits in the veneer sheets (partial $R^{2}=0.17$ ). For percentage recovery of veneer, veneer sheet end splits were associated with only a minor portion of the variation (partial $R^{2}=0.02$ ) while log end check index and live knot index (partial $R^{2 \text { s }}$ of 0.36 and 0.41 , respectively) were the traits with the strongest associations. Interestingly, these latter two traits were also associated with most of the variation in value per $\mathrm{m}^{-3}$ (partial $R^{2}$ s of 0.34 and 0.38 , respectively), while average circularity was associated with only a small proportion (partial $R^{2}=0.05$ ). For value tree ${ }^{-1}$, average small end diameter showed an overwhelmingly dominant association (partial $R^{2}=0.80$ ) while three other traits had relatively minor associations - live knot index and average circularity (partial $R^{2}$ s of 0.09 and 0.02 , respectively).

For the lower logs, the greatest proportion of variation in veneer grade was associated with variations in veneer sheet end split index and dead knot index (partial $R^{2}$ s of 0.42 and 0.35 , respectively), while variations in the live knot index and hole index of veneer sheets were associated with minor portions of the variation (partial $R^{2}$ s of 0.02 ). For veneer recovery, variation in sweep was associated with over $50 \%$ of the total variation (partial $R^{2}=0.53$ ), with taper and circularity being associated with somewhat smaller proportions of the variation (partial $R^{2}$ s of 0.20 and 0.06 , respectively); together these three traits were associated with nearly $80 \%$ $\left(R^{2}=0.79\right)$ of the variation in recovery. Interestingly, the same three traits were also associated with around $80 \%$ of

Table 4 Correlation coefficients $(r)$ based on tree mean data for tree, log, and veneer properties with veneer grade, veneer recovery, and log and tree values - results are only presented for traits which showed one or more significant correlations

\begin{tabular}{|c|c|c|c|c|c|}
\hline Correlated trait & $\begin{array}{l}\text { Average veneer } \\
\text { grade }\end{array}$ & Veneer recovery $(\%)$ & $\begin{array}{l}\text { Veneer } \\
\text { value tree }\end{array}$ & $\begin{array}{l}\text { Total } \\
\text { value tree }\end{array}$ & $\begin{array}{l}\text { Total } \\
\text { value } \mathrm{m}^{-3}\end{array}$ \\
\hline $\mathrm{DBH}$ & -0.08 & $0.36^{*}$ & $0.85 *$ & $0.89 *$ & $0.41 *$ \\
\hline Tree volume under bark & -0.27 & $0.52 *$ & $0.86^{*}$ & $0.89 *$ & $0.56^{*}$ \\
\hline Average small end diameter of $\log \mathrm{s}^{\mathrm{a}}$ & -0.20 & $0.49^{*}$ & $0.91 *$ & $0.94 *$ & $0.54^{*}$ \\
\hline Average taper & 0.18 & $-0.38 *$ & -0.15 & -0.10 & $-0.36^{*}$ \\
\hline Average log end check index & 0.04 & $-0.53 *$ & $-0.76^{*}$ & $-0.77^{*}$ & $-0.53^{*}$ \\
\hline Average veneer end split index & $0.40 *$ & -0.37 & -0.22 & -0.21 & -0.23 \\
\hline Dead knot index & $0.63 *$ & -0.32 & -0.27 & -0.24 & -0.36 \\
\hline Live knot index & $0.50^{*}$ & $-0.58 *$ & -0.28 & -0.22 & $-0.57^{*}$ \\
\hline
\end{tabular}

$* P<0.05$

${ }^{\text {a }}$ Average small end diameter is the average of $\operatorname{logs} 1,3$, and 5 
Table 5 Results from stepwise regression analyses, for lower, middle, and upper logs combined and separately for the three log positions to

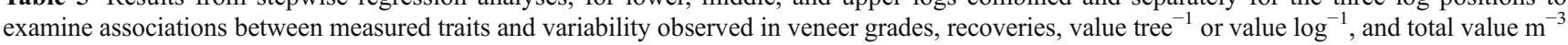

\begin{tabular}{|c|c|c|c|c|c|c|c|c|}
\hline \multirow[t]{2}{*}{ Log position } & \multicolumn{2}{|c|}{ Average veneer grade } & \multicolumn{2}{|l|}{ Veneer recovery $(\%)$} & \multicolumn{2}{|c|}{$\begin{array}{l}\text { Value-RMB tree }{ }^{-1}(\text { all } 3 \operatorname{logs}) \\
\text { or RMB } \log ^{-1}\end{array}$} & \multicolumn{2}{|l|}{ Total value $\mathrm{RMB} \mathrm{m}^{-3}$} \\
\hline & Correlated trait & Partial $R^{2}$ & Correlated trait & Partial $R^{2}$ & Correlated trait & Partial $R^{2}$ & Correlated trait & Partial $R^{2}$ \\
\hline \multirow{4}{*}{$\begin{array}{l}\text { Logs } 1 \text {, } \\
3 \text {, and } 5 \\
\text { combined }\end{array}$} & Dead knot index & 0.54 & Log end check index & 0.36 & Small end diameter & 0.80 & Live knot index & 0.38 \\
\hline & $\begin{array}{l}\text { Veneer end split } \\
\text { index }\end{array}$ & 0.17 & Live knot index & 0.41 & Live knot index & 0.09 & Log end check index & 0.34 \\
\hline & - & - & Veneer end split index & 0.02 & Average circularity & 0.02 & Average circularity & 0.05 \\
\hline & Combined $\mathrm{R}^{2}$ & 0.71 & Combined $R^{2}$ & 0.79 & Combined $R^{2}$ & 0.91 & Combined $R^{2}$ & 0.77 \\
\hline \multirow[t]{5}{*}{$\begin{array}{l}\log 1 \\
\quad \text { (lower) }\end{array}$} & $\begin{array}{l}\text { Veneer end split } \\
\text { index }\end{array}$ & 0.42 & Sweep & 0.53 & Sweep & 0.38 & Sweep & 0.62 \\
\hline & Dead knot index & 0.35 & Taper & 0.20 & Small end diameter & 0.39 & Taper & 0.16 \\
\hline & Live knot index & 0.02 & Circularity & 0.06 & Taper & 0.04 & Circularity & 0.03 \\
\hline & Hole index & 0.02 & - & - & Live knot index & 0.02 & - & - \\
\hline & Combined $R^{2}$ & 0.81 & Combined $R^{2}$ & 0.79 & Combined $R^{2}$ & 0.83 & Combined $R^{2}$ & 0.81 \\
\hline \multirow{5}{*}{$\begin{array}{l}\log 3 \\
\quad \text { (middle) }\end{array}$} & Dead knot index & 0.50 & Small end diameter & 0.35 & Small end diameter & 0.82 & Small end diameter & 0.36 \\
\hline & $\begin{array}{l}\text { Veneer end split } \\
\text { index }\end{array}$ & 0.16 & Veneer end split index & 0.09 & Sweep & 0.05 & Sweep & 0.14 \\
\hline & - & - & Dead knot index & 0.07 & Log end check index & 0.02 & $\begin{array}{l}\text { Log end check } \\
\text { index }\end{array}$ & 0.07 \\
\hline & - & - & - & - & $\begin{array}{l}\text { No. knots visible } \\
\text { on } \log \end{array}$ & 0.01 & Hole index & 0.04 \\
\hline & Combined $R^{2}$ & 0.67 & Combined $R^{2}$ & 0.51 & Combined $R^{2}$ & 0.90 & Combined $R^{2}$ & 0.61 \\
\hline \multirow[t]{4}{*}{$\begin{array}{l}\log 5 \\
\quad \text { (upper) }\end{array}$} & $\begin{array}{l}\text { Veneer end split } \\
\text { index }\end{array}$ & 0.31 & Sweep & 0.45 & Small end diameter & 0.82 & Sweep & 0.45 \\
\hline & Dead knot index & 0.17 & Small end diameter & 0.41 & Sweep & 0.04 & Small end diameter & 0.43 \\
\hline & Sweep & 0.12 & - & - & Log end check index & 0.02 & - & - \\
\hline & Combined $R^{2}$ & 0.60 & Combined $R^{2}$ & 0.86 & Combined $R^{2}$ & 0.93 & Combined $R^{2}$ & 0.88 \\
\hline
\end{tabular}

the variation in value $\mathrm{m}^{-3}$ (combined partial $R^{2}=0.81$ ), with sweep being of greatest importance (partial $R^{2}$ of 0.62 ) while taper and circularity were less so (partial $R^{2}$, s of 0.16 and 0.03 , respectively). For value $\log ^{-1}$ (of lower logs) variation in sweep was also associated with a major proportion the variation (partial $R^{2}=0.38$ ) and was of equal importance to small end diameter (partial $R^{2}=0.39$ ).

The stepwise regressions for the middle and upper logs gave quite different results to the lower logs, particularly in respect to values $\log ^{-1}$ (Table 5). For this latter parameter, variation in small end diameter was associated with a major portion of the variability (partial $R^{2}$ s both 0.82 ); while sweep and log end check index were associated with minor portions of the variation in this value trait (partial $R^{2}$ s of 0.02 to 0.05 for $\operatorname{logs} 3$ and 5). For total value $\mathrm{m}^{-3}$, sweep and small end diameter together were associated with a major portion of the variation (combined $R^{2}$ s of 0.50 and 0.86 in $\operatorname{logs} 3$ and 5 , respectively). For veneer grades obtained from the middle $\operatorname{logs}(\log 3)$, dead knot index was the key trait associated with the variation (partial $R^{2}=$ 0.50 ) and veneer end split index was associated with a lesser proportion of the variability (partial $R^{2}=0.16$ ). For veneer grades from upper logs, the importance of these traits was reversed with veneer end split index being associated with more of the grade variation (partial $R^{2}=0.31$ ) than dead knot index (partial $R^{2}=0.17$ ). For percentage recovery of veneer from both middle and upper logs, small end diameter was one of the key traits associated with the variation (partial $R^{2 \text { s }}$ of 0.35 and 0.41 in $\operatorname{logs} 3$ and 5 , respectively). In the middle logs the other traits of importance to recovery were veneer end split index and dead knot index (partial $R^{2}$ s of 0.09 and 0.07 , respectively) but in the upper logs the trait of sweep was of major importance (partial $R^{2}$ of 0.45 ).

\section{Discussion}

Some of the variation observed among clones in this study for volume and $\log$ characteristics was to be expected; previous studies have reported variation among commercial clones of eucalypt hybrids and pure species at similar sites in southern China (Luo et al. 2012; Mo et al. 2003) and elsewhere (Borralho et al. 1992). Interestingly though, the clones with the highest volumes in this study were both 
hybrids of Eucalyptus grandis, clone 1 an E. grandis $\times$ tereticornis hybrid and clone 5 an $E$. urophylla $\times$ grandis hybrid. Indeed, all five clones in this study with $E$. grandis in their parentage (see Table 1) also ranked in the top five to six clones by recovery percentage, veneer and total value tree $^{-1}$ and total value $\mathrm{m}^{-3}$. This suggests that $E$. grandis might impart more favorable log form and wood properties for veneer production than do the other parent species represented in the group of hybrid clones studied, however further research would be needed to prove this definitively.

That significantly lower recoveries of peeled veneer were obtained from lowest logs than middle and upper logs in this study echoes results obtained from young hybrid poplar trees (DBH class $\leq 25 \mathrm{~cm}$ ) by Spinelli et al. (2008); they obtained recoveries of $55 \%$ of rotary peeled veneer from the lowest (butt) logs compared to $67 \%$ for other (upper) logs (in both cases peeling to down to core diameters of $6.5 \mathrm{~cm}$ ). In contrast, Blakemore et al. (2010) obtained significantly higher veneer recoveries from the lowest logs of both pruned and unpruned 21 -year-old $E$. nitens (64 and $58 \%$, respectively) than from both the second and third logs $(54 \%$ for the second and $27 \%$ for the third, from unpruned trees), though the core diameter was not specified in their report. Decreases in green recoveries going up the trees in their study were associated with decreasing small end diameters of the logs. That the decreases in small end diameter with increasing height of log position observed in our study did not manifest in decreasing green veneer recoveries, as expected based on results elsewhere on veneer recovery from eucalypts, is attributable to an over-riding impact of sweep and taper of differences between logs from different heights (Tables 3 and 5).

Results obtained from our study for grade proportions for middle and upper logs, which were very similar and showed no significant differences, also contrasted to Blakemore et al.'s (2010) E. nitens results. In their study significant differences were found for both pruned and unpruned trees in grade recoveries between the second and third logs, with the former providing markedly superior grade recoveries.

All but two of the clones in this current study provided veneer recoveries over $40 \%$; recovery rates that compare favorably with those obtained from older and larger diameter eucalypt logs in two Australian studies. Thomas et al. (2009) reported recoveries of 30 to $55 \%$ for rotary peeled veneer from Eucalyptus dunnii logs varying in ages from 13 to 34 years and of about 20 to $55 \%$ from 34-year-old logs of Eucalyptus agglomerata, E. grandis, Eucalyptus pilularis, and Eucalyptus saligna, though they did not specify the core diameter peeled down to. Blakemore et al. (2010) obtained a $45 \%$ recovery from unpruned 21 -year-old $E$. nitens, but a somewhat higher recovery of $58 \%$ from pruned logs of the same species. Interestingly, both a study on poplar clones and also one on larger diameter logs from eucalypt clones obtained markedly higher recoveries (though again the core diameters were not specified) - averaging around 60 to $70 \%$ for 14- to 17-year-old poplar logs (Baonza and Oliva 2002 ) and 57 to $68 \%$ of 12 -year-old E. urophylla $\times$ grandis logs (Peng et al. 2011).

In this current study, log defects associated with branches proved to be major limitations to production of higher grade veneers. While there was significant variation in defects associated with branches between the clones, separate studies have suggested that the silvicultural treatment of stem pruning (at an appropriate age) might be the best way of reducing such defects in eucalypt logs (Blakemore et al. 2010).

While results obtained in the current study for recoveries from middle and upper logs were in general agreement with those of Thomas et al. (2009) and generally accepted wisdom (Shield 1995; Brown and Beadle 2008) that percentage recovery increases with increasing small end diameter, it was a somewhat different situation for the lowest logs. In the latter logs, percentage recovery of veneer was determined predominantly by sweep and taper.

Unfortunately, it was beyond the scope and resources of the current study to examine the quality of the veneer sheets obtained in this study beyond the visual traits. Veneer traits such as stiffness, elasticity, and hardness are known to have important impacts on the subsequent strength and other important properties of plywood made from them (Brown and Beadle 2008). Examining such traits in further research on veneer and plywood produced from young, small diameter eucalypt logs seems well warranted in order to support this burgeoning industry in China.

\section{Conclusion}

Large significant variations were found among clones for tree growth and log form traits, veneer grades and recoveries, and also for measures of commercial values per unit volume, per $\log$, and per tree. The five clones having $E$. grandis involved in their parentage all ranked in the best six (out of 11) for grade, recovery percentages, and all value traits. For most of the clones studied, the veneer recoveries achieved compare favorably with those from unpruned plantation-grown eucalypt logs of much larger diameters and older ages in Australian studies on a range of sub-tropical eucalypt species, including $E$. grandis and $E$. saligna which were two of the key species involved in six of the clones for this current study. The potential to achieve such recoveries of reasonable grade veneers from eucalypt clones at just age 5 years is undoubtedly beneficial to both processors and local eucalypt plantation growers whose young logs are in strong demand for such end uses.

While this study generally confirmed the influence of small end diameter on the value of a single log section, other traits were of overriding importance in determining veneer recoveries from lower (bottom) logs, especially 
sweep and taper. Lower logs proved inferior to upper logs for veneer recovery and veneer value, despite having significantly larger small end diameters; the third (middle) logs provided the highest veneer values. Thus, in a situation of plentiful log supply, processors could benefit from not buying the butt/lowest logs.

Defects associated with knots proved to be key factors limiting veneer grades achieved in this study. However, given the relatively low variation in grades observed overall in this study and the small value margins associated with grade increments, there is relatively little incentive at pres- ent for growers and/or processors to invest in treatments, such as silvicultural pruning, to improve veneer grades.

Acknowledgments Thanks are due to the China Eucalypt Research Center for supporting this study and to JG Cao, Y Jiang, FY Han, HL Zhang, LL He, PJ Zhang, and DY Wei for assistance with data collection. We are also grateful to two anonymous reviewers for constructive comments and suggestions on earlier drafts of this manuscript.

Funding Funding for this study was provided by China's State Forest Administration through the project 'Studies to improve key technologies on ecological management and utilization' (Project no. 201104003).

\section{Appendix 1}

Table 6 Grading criteria adopted in this study - these grades are those specified in the "People's Republic of China Veneer Grading Standard "Rotary Veneer (LY/T 1599-2002)" (issued 12/10/2002)

\begin{tabular}{|c|c|c|c|c|c|}
\hline Defect & Grade 1 & Grade 2 & Grade 3 & Grade 4 & Grade 5 \\
\hline Pin holes & $\begin{array}{l}\leq 2 \mathrm{~mm} \text { : no limitation } \\
\text { on number }\end{array}$ & No limitation & No limitation & No limitation & No limitation \\
\hline Live knots - tight & $\begin{array}{l}\leq 5 \mathrm{~mm}: \leq 5 \text { per sheet, } \\
\text { knots not split }\end{array}$ & $\begin{array}{l}\leq 5 \mathrm{~mm} \text { : no limitation } \\
\text { per sheet }\end{array}$ & No limitation & No limitation & No limitation \\
\hline Dead knots & $\begin{array}{l}2 \text { to } 4 \mathrm{~mm}: \leq 2 \mathrm{~m}^{-2} \\
\text { no limitation for } \\
\quad<2 \mathrm{~mm}\end{array}$ & $\begin{array}{l}\geq 4 \mathrm{~mm}: \leq 3 \mathrm{~m}^{-2} \\
\quad \text { no limitation for } \\
\quad<4 \mathrm{~mm}\end{array}$ & $\begin{array}{l}\geq 15 \mathrm{~mm}: \leq 4 \mathrm{~m}^{-2} \\
\quad \text { no limitation for } \\
\quad<15 \mathrm{~mm}\end{array}$ & $\begin{aligned} \leq & 30 \mathrm{~mm}: \mathrm{no} \\
& \text { limitation } \mathrm{m}^{-2}\end{aligned}$ & No limitation \\
\hline Holes-unfilled & None & $\begin{array}{l}\leq 5 \mathrm{~mm}: \leq 4 \text { per sheet; } \\
\text { no limitation for } \\
\leq 2 \mathrm{~mm}\end{array}$ & $\begin{array}{l}\leq 15 \mathrm{~mm}: \leq 8 \text { per } \\
\text { sheet; no limitation } \\
\text { for } \leq 2 \mathrm{~mm}\end{array}$ & $\begin{array}{l}\leq 20 \mathrm{~mm}: \text { no } \\
\text { limitation if } \\
\text { not in clustered }\end{array}$ & $\begin{array}{l}\leq 20 \mathrm{~mm}: \text { no } \\
\text { limitation if } \\
\text { not clustered }\end{array}$ \\
\hline Unfilled splits & $\begin{array}{l}\leq 2 \text { enclosed, total } \\
\text { length } \leq 200 \mathrm{~mm}\end{array}$ & $\begin{array}{l}\text { Width } \leq 1.5 \mathrm{~mm} \text { and } \\
\text { length } \leq 400 \mathrm{~mm} \text { : } \\
\leq 4 \text { per sheet }\end{array}$ & $\begin{array}{l}\text { Width } \leq 3 \mathrm{~mm} \text { and } \\
\text { length } \leq 600 \mathrm{~mm} \text { : } \\
\leq 4 \text { per sheet }\end{array}$ & $\begin{array}{l}\text { Width } \leq 5 \mathrm{~mm}^{1} \\
\text { wider splits } \\
\text { must be repaired }\end{array}$ & $\begin{array}{l}\text { Width } \leq 5 \mathrm{~mm}^{1} ; \\
\text { wider splits } \\
\text { must be repaired }\end{array}$ \\
\hline Bark and resin pocket & None & None & $\begin{array}{l}\text { Width } \leq 4 \mathrm{~mm} \text { and } \\
\text { length } \leq 50 \mathrm{~mm} \text { : } \\
\leq 2 \text { per sheet }\end{array}$ & No limitation & No limitation \\
\hline Staining - mechanical or fungal & None & None & $\leq 3 \%$ total area & $\leq 5 \%$ total area & $\leq 5 \%$ total area \\
\hline Discoloration — natural & None & $\begin{array}{c}\text { Slight, } \leq 5 \% \\
\text { total area }\end{array}$ & $\begin{array}{l}\text { Slight, } \leq 30 \% \\
\text { total area }\end{array}$ & No limitation & No limitation \\
\hline
\end{tabular}

\section{References}

Anonymous (2011) Exponential growth in Chinese wood processing seen. Friday Offcuts 28/01/2011.

Baonza MV, Oliva AG (2002) Rendimiento y calidades de chapa en clones de chopo a diferentes alturas del fuste. Invest Agr Sist Recur For 11:311-312

Blakemore P, Morrow A, Washusen R, Harwood C, Wood M, Ngo D (2010) Evaluation of thin-section quarter-sawn boards and rotary veneer from plantation-grown Eucalyptus nitens. Technical Report 202. Cooperative Research Centre for Forestry, Sandy Bay

Borralho NMG, Almeida IM, Cotterill PP (1992) Genetic control of growth of young Eucalyptus globulus clones in Portugal. Sil Gen 41:100-105

Brown AG, Beadle CL (2008) Plantation eucalypts for high-value timber-enhancing investment through research and development. Publication No. 08/Project No. CVF-2A. RIRDC, Barton
Chen SX, Wu ZH, Li ZH, Xie YJ, Li TH, Zhou QY, Arnold R (2010) Selection of eucalypt species for solid wood production in southern China. J Trop For Sci 22:308-316

CNAS (2002) People's Republic of China Veneer Grading Standard: Rotary Veneer (LY/T 1599-2002). Issued 12/10/2002. National Accreditation Service for Conformity Assessment, Beijing

Fang SZ (2008) Silviculture of poplar plantation in China: a review. Ying Yong Sheng Tai Xue Bao 19:2308-2316 [Article in Chinese]

ITTO (2011) Report from China. ITTO Trop Timber Mark Report 16:12-13

Jiang X, Ye K, Lu J, Zhao Y, Yin Y (2007) Guide on utilisation of Eucalyptus and Acacia plantations in China for solid wood products. Science Press, Beijing

Luo J, Arnold RJ, Cao J, Lu W, Ren S, Xie Y (2012) Variation in volume growth, wood density and pulp yield among eucalypt clones across sites and implications for deployment strategies. J Trop For Sci 24:70-82

Mo X, Peng S, Long T, Chen W, Yang X (2003) Important traits and combined evaluation of eucalypt clones. In: Wei RP, Xu D (eds) Eucalypt plantations - research, management and development. World Scientific, Singapore, pp 102-109 
Peng Y, Chen SX, Washusen R, Northway R, Xie YJ, Wu ZH (2011) Wood properties, veneer production and veneer's economic value of 5 Eucalyptus urophylla $\times$ E. grandis clones. Euc Sci Tech 28:1-9 [In Chinese]

Petry M, Lei Z, Zhan S (2010) China Forest Products Annual Report 2010. USDA Gain Report CH100042. USDA Foreign Agricultural Service, Beijing

Ren S, Luo J, Xie Y, Peng Y, Chen J, Lu W, Jiang Y (2010a) Study on factors influencing veneer recovery ratio and value of eucalypt wood. Euc Sci Tech 27:1-7 [In Chinese]

Ren S, Luo J, Peng Y, Xie Y, Lu W, Cao J, Jiang Y (2010b) A study on veneer recovery ratio and value of eucalypt clones. Acta Prataculturae Sin 19:46-54 [In Chinese]

SAS Institute Inc (1999) SAS/STAT User's guide, version 8. SAS Institute Inc., Cary

Shield ED (1995) Plantation grown eucalypts: utilisation for lumber and rotary veneers - primary conversion. In: Proc. "Seminário Internacional de Utilização da Madeira de Eucalipto
Para Serraria." 5-6 April, 1995, São Paulo, Brazil. pp. 133-139

Spinelli R, Hartsough BR, Pottle SJ (2008) On-site veneer production in short-rotation hybrid poplar plantations. For Prod J 58:66-71

Thomas D, Joe B, Austin S, Henson M (2009) Characterisation of plywood properties manufactured from plantation grown eucalypts. Final Report-Project No: PRB046-0809. Forestry and Wood Products Australia, Melbourne

Turnbull JW (2007) Development of sustainable forestry plantations in China: a review. ACIAR Impact Assessment Series Report No. 45. ACIAR, Canberra

Wan M (2009) Analysis of China's primary wood products marketSawnwood and Plywood Thesis, University of Helsinki

Wood Markets (2011) China Bulletin-May 2011. International Wood Markets Group Inc, Canada

Yang JL (2005) The impact of log-end splits and spring on sawn recovery of 32-year-old plantation Eucalyptus globulus labill. Holz als Roh und Werkstoff 63:442-448 